\title{
HUBUNGAN KEKUATAN OTOT LENGAN DAN KESEIMBANGANSTATISDENGAN JAUHNYA LEMPARAN TURBO
}

\author{
Adi Suriatno ${ }^{1}$, Rusdiana Yusuf ${ }^{2}$ \\ Pendidikan Olahraga Dan Kesehatan, FPOK IKIP Mataram \\ adi.suriatno@yahoo.com
}

\begin{abstract}
This study aims to determine whether there is a Relationship of Muscle Arm Strength And Stainless Equilibrium With Turbo Shot Deep In "The population of this study using all with the number of research samples as many as 25 people so this research uses population study techniques. The data collection technique is using the test method of deed and documentation. Arm muscle strength instruments are Push Up, static balance using a stork stand, and turbo throw using 2 turbo. Technique of data analysis using double correlation method, from result of research at 5\% significant level stated that there is relation of arm muscle strength with throw away turbo where the value of $r$ value count bigger than $r$ table $(0,617>0,396)$, So the final result of this research is no relationship Arm Muscle Strength and Static Balance with Remote Turbo Shot on Lesson Year 2019.
\end{abstract}

Keywords: Arm muscle strength, Static Balance and Turbo Throw.

\begin{abstract}
Abstrak
Penelitian ini bertujuan untuk mengetahui apakah ada Hubungan Kekuatan Otot Lengan Dan Keseimbangan Stastis Dengan Jauhnya Lemparan Turbo Pada Siswa Kelas V SDN 2 Gerunung Tahun Pelajaran 2016/2017" Populasi penelitian ini menggunakan seluruh siswa kelas VSDN2Gerunung dengan jumlah sampel penelitian sebanyak 25 orang sehingga penelitian ini menggunakan teknik studi populasi.Tehnik pengumpulan data adalah menggunakan metode test perbuatan dan dokumentasi. Instrument kekuatan otot lengan yaitu Push Up, keseimbangan statis menggunakan stork stand, dan lempar turbo menggunakan 2 buah turbo. Tehnik analisis data menggunakan metode korelasi ganda, dari hasil penelitian tersebut pada taraf signifikan 5\% dikemukakan bahwa ada hubungan kekuatan otot lengan dengan jauhnya lemparan turbo dimana nilai rhitung lebih besar dari rtabel $(0,617>0,396)$, Sehingga hasil akhir dari penelitian ini adalah ada Hubungan Kekuatan Otot Lengan dan Keseimbangan Statis dengan Jauhnya Lemparan Turbo Pada Siswa Kelas V SDN 2 Gerunung Tahun Pelajaran 2016//2017.
\end{abstract}

Kata kunci :Kekuatan Otot Lengan, Keseimbangan Statis dan Lempar Turbo.

\section{PENDAHULUAN}

Atletik merupakan salah satu cabang olahraga tertua di dunia dan sekaligus merupakan ibu dari semua cabang olahraga sehingga di dalam kurikulum sudah dimasukkan dan tujuannya untuk memperkenalkan secara dini kepada siswa cabang olahraga tersebut, karena sekolah merupakan tempat yang tepat dan efektif untuk menyalurkan bakat dan minat para siswa. Dengan adanya minat para siswa tersebut diharapkan mampu memberikan pencapaian secara maksimal sehingga siswa mampu berkompetisi di tingkat daerah, regional, nasional bahkan di tingkat internasional.

Berbagai hasil yang diraih oleh atletatlet terutama di NTB merupakan buah hasil dari ketekunan dan keyakinan sehingga mampu memberikan yang tebaik bagi masyarakat NTB pada cabang olahraga atletik.Lempar Turbo membutuhkan kekuatan untuk mencapai hasil yang maksimal. Adanya hubungan positif antara tingkat kondisi fisik dengan pencapaian prestasi tersebut mendorong penulis membuktikan hubungan kekuatan otot lengan dan keseimbangan statis dengan jauhnya lemparan turbo. Cabang 
olahraga atletik dalam setiap kali diadakannya lomba, baik di tingkat daerah, nasional, regional, dan internasional.Seorang atlit sering mengikuti lomba di dua nomor sekaligus. Termasuk diantaranya keseimbangan sekaligus pada saat melakukan lemparan, dan lain sebagainya.Lempar Turbo membutuhkan kekuatan untuk mencapai hasil yang maksimal. Adanya hubungan positif antara tingkat kondisi fisik dengan pencapaian prestasi tersebut mendorong penulis membuktikan hubungan kekuatan otot lengan dan keseimbangan statis dengan jauhnya lemparan turbo. Cabang olahraga atletik dalam setiap kali diadakannya lomba, baik di tingkat daerah, nasional, regional, dan internasional.Seorang atlit sering mengikuti lomba di dua nomor sek aligus.

Termasuk diantaranya keseimbangan sekaligus pada saat melakukan lemparan, dan lain sebagainya.

Mengingat pentingnyan unsur kekuatan otot lengan dan keseimbangan dalam cabang olahraga atletik, maka perlu diteliti tentang hubungan kekuatan otot lengan dan keseimbangan statis.Untuk itu penulis memotivasi mengangkat judul "Hubungan kekuatan Otot Lengan dan Keseimbangan Statis Dengan Jauhnya Lemparan Turbo

\section{Kekuatan otot lengan}

Mengingat betapa pentingnya latihan Kekuatan Otot Lengan di dalam suatu cabang olahraga, termasuk cabang olahraga lempar turbo maka latihan Kekuatan Otot Lengan perlu dianalisa tentang arti dan tujuan serta jenis-jenis latihan dan apa saja unsur-unsur yang berhubungan dengan unsur penunjang pembinaan yang berkelanjutan untuk dapat mencapai prestasi yang diinginkan, Kekuatan Otot Lengan dapat menunjang segala aktifitas baik di dalam latihan maupun di dalam pertandingan .

Sehubungan dengan hal tersebut maka dalam latihan kondisi Kekuatan Otot Lengan secara berurutan dan teratur, sehingga dapat melakukan gerakan seefisien mungkin, pemberian latihan kondisi kekuatan otot lengan adalah untuk meningkatkan kemampuan kekuatan otot lengan sehingga dapat melakukan gerakan-gerakan sampai kebatas maksimal untuk dapat mencapai perestasi dari gerakan yang dimaksud. Peningkatan kemampuan kekuatan otot lengan adalah dengan melalui peningkatan kemampuan kerja organ-organ tubuh.

Kekuatan otot lengan adalah merupakan modal utama dalam setiap kegiatan olahraga "Kekuatan atau strength adalah komponen kondisi fisik seseorang tentang kemampuannya dalam mempergunakan otot untuk menerima beban sewaktu bekerja.Jadi kekuatan otot dapat dikatakan sebagai daya atau kemampuan yang dapat dikeluarkan oleh otot untuk membangkitkan tegangan (kontraksi) secara maksimum dari satu atau sekelompok otot.

Meskipun banyak aktivitas olahraga yang lebih banyakmemerlukan kelincahan kecepatan,koordinasi, keseimbangan, reaksi dan sebagainya, akan tetapi dari berbagai faktor-faktor tersebut tetap membutuhkan adanya faktor kekuatan agar diperoleh hasil yang lebih baik. Dengan kata lain kekuatan otot lengan merupakan kekuatan yang dihasilkan oleh satu atau sekelompok otot lengan yang berkontraksi secara maksimal, dan uraian pelaksanaannya menggunakan push up dengan cara sebagai berikut :

a. Teste menelungkup,untuk laki-laki,kepala, punggung, sampai dengan tungkai dalam posisi lurus. Untuk perempuan, kepala dan punggung lurus, sedangkan tungkai ditekuk.

b. Kedua telapak tangan diletakkan di lantai disamping dada dan jari-jari tangan ditutup dan kedepan.

c. Kedua telapak kakidirapatkan. Untuk lakilaki jari-jari kaki bertumpu di lantai,sedangkan perempuan tungkai ditekuk.

d. Saat sikap telungkup, hanya dada yang menyentuh lantai, sedangkan kepala, perut dan tungkai bawah terangkat.

e. Dari sikap telungkup, angkat tubuh dengan meluruskan kedua lengan, kemudian turunkan lagi tubuh dengan membengkokkan kedua lengan sehingga dada menyentuh lantai.

f. Setiap kali mengangkat dan menurunkan tubuh, kepala, punggung dan tungkai tetap lurus. 
g. Setiap kali tubuh terangkat dihitung sekali.

h. Pelaksanaan telungkup angkat tubuh dilakukan sebanyak mungkin selama 30 detik Pelaksanaan dinyatakan betul bila saat tubuh terangkat, kedua tangan lurus, kepala, punggung, dan tungkai lurus.

\section{Keseimbangan statis}

Stork stand test (untuk mengukur keseimbangan statis).Tes ini berdiri tegak dengan satu kaki tumpu (kaki kanan atau kaki kiri). ujung kaki diletekkan di samping lutut kaki yang lain dan letakkan kedua tangan pada pinggang (bertolak pinggang).

Cara pelaksanaannya adalah bersamaan dengan aba-aba "ya" ketika stop watch dijalankan peserta tes memposisikan dirinya mengangkat tumitnya dari lantai atau menjinjit, pertahankan sikap ini selama mungkin tanpa tumit menyentuh lantai atau menggeserkan ujung telapak kaki dari tempat semula.Stop watch akan diberhentikan apabila, tumit peserta tes menyentuh lantai, menggeserkan ujung telapak kaki dari samping lutut, memindahkan kedua tangan dari pinggang atau tidak dapat mempertahankan keseimbangan tubuhnya, dan kesempatan diberikan selama 3 kali.

\section{Lempar Turbo}

Lempar lembing anak-anak atau turbo diawali dengan awalan 5 meter. Setelah melakukan awalan pendek peserta melempar lembing anak atau turbo ke area lemparan dengan dibatasi garis lempar. Setiap peserta melakukan dua lemparan.Setiap lemparan diukur dengan memberi tanda yang ditarik 90 derajat ke arah garis batas lempar dan dicatat per interval $25 \mathrm{~cm}$. Bila lembing jatuh diantara atau tengah garis $25 \mathrm{~cm}$ maka akan dibulatkan ke atas. Jumlah jarak terbaik dari dua lemparan masing-masing.

\section{METODE PENELITIAN}

Penelitian ini menggunakan metode eksperimen dengan menggunakan tehnik sampling jenuh karena menggunakan seluruh siswa kelas V SDN 2 Gerunung dan menggunakan studi populasi. Metode eksperimen merupakan suatu cara melakukan suatu percobaan dan mengamati hasil dari percobaan tersebut kemudian dituangkan dalam sebuah catatan.
Penelitian ini ditujukan untuk mengetahui hubungan antara dua variable bebas dan satu vaiabel terikat dengan upaya untuk melihat hubungan yang dari semua variable tersebut, dan desain penelitannya adalah sebagai berikut :

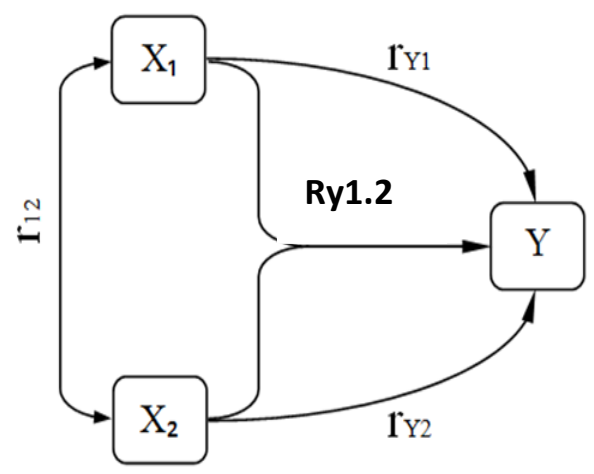

Gambar 3.1 Rancangan penelitian korelasi ganda

(Maksum, A. 2009 :52).

Keterangan:

Ry1.2 = Koefisien linier 3 variabel

ry1 = Koefisien korelasi variable Y dan X1

ry2 = Koefisien korelasi variable Y dan X2

r1.2 = Koefisien korelasi variable $\mathrm{X} 1$ dan $\mathrm{X} 2$

penelitian ini bertujuan untuk mengetahui besarnya hubungan antara kekuatan otot lengan dan keseimbangan statis dengan jaunhya lemparan turbo. Adapun (X1) kekuatan otot lengan, (X2) keseimbangan statis merupakan variable bebas dan lemparan turbo (Y) merupakan variable terikat.

Dalam instrument kegiatan ini mengunakan hanya satu tes saja yaitu untuk instrument kekuatan otot lengan menggunakan push up, keseimbangan statis mengguakan instrument stork stand, dan lempar turbo menggunakan dua buah turbo. Tehnik dalam pengolah data ini menggunakan rumus korelasi berganda yaitu rumus korelasi berganda

$$
R_{y_{\cdot 12}}=\sqrt{\frac{r_{y_{1}}^{2}+r_{y_{2}}^{2}-2 r_{y_{1}} r_{y_{2}} r_{y_{12}}}{1-r_{12}^{2}}}
$$

Keterangan:

$\mathrm{Ry}_{1.2}=$ Koefisien linier 3 variabel

$\mathrm{ry}_{1}=$ Koefisien korelasi variable 
Y dan X1

$\mathrm{ry}_{2}=$ Koefisien korelasi variable

$$
\mathrm{Y} \text { dan X2 }
$$

\section{HASIL DAN PEMBAHASAN}

\section{Mendistribusikan data kedalam rumus}

a. Korelasi antara $X_{1}$ dengav $\mathrm{y}$

$$
\begin{gathered}
r_{\mathrm{y}_{1}}=\frac{\mathrm{n} \sum \mathrm{x}_{1} \mathrm{y}-\left(\sum \mathrm{y}\right)\left(\sum \mathrm{x}_{1}\right)}{\sqrt{\left(\mathrm{n} \sum \mathrm{y}^{2}-\left(\sum \mathrm{y}\right)^{2}\right)}\left(\mathrm{n} \sum \mathrm{x}_{1}^{2}-\left(\sum \mathrm{x}_{1}\right)^{2}\right)} \\
r_{y^{1}} \\
=\frac{27808-27312,5}{\sqrt{(14512,17-14101,56)}(55300-52900)} \\
r_{y_{1}}=\frac{496,25}{\sqrt{985464}} \\
\mathrm{r}_{\mathrm{y}_{1}}=\frac{496,25}{992,705} \\
\mathrm{r}_{\mathrm{y}^{1}}=0,499
\end{gathered}
$$

b. Korelasi antara $\mathrm{X}_{2}$ dengan $\mathrm{Y}$

$$
\mathrm{r}_{\mathrm{y}_{2}}=\frac{\mathrm{n} \sum \mathrm{x}_{2} \mathrm{y}-\left(\sum \mathrm{y}\right)\left(\sum \mathrm{x}_{2}\right)}{\sqrt{\left(\mathrm{n} \sum \mathrm{y}^{2}-\left(\sum \mathrm{y}\right)^{2}\right)}\left(\mathrm{n} \sum \mathrm{x}_{2}^{2}-\left(\sum \mathrm{x}_{2}\right)^{2}\right)}
$$$$
r_{y_{2}}=\frac{72273,75-70775}{\left.\sqrt{(25.14512,17)}(25 \cdot 14101,56)^{2}\right)}
$$$$
\mathrm{r}_{\mathrm{y}_{2}}=\frac{1498,75}{\sqrt{(379800)}(355216)}
$$$$
\mathrm{r}_{\mathrm{y}_{2}}=\frac{401,61}{\sqrt{24584}}
$$$$
r_{\mathrm{y}_{2}}=\frac{401,61}{10094436}
$$$$
\mathrm{r}_{\mathrm{y}_{2}}=0,471
$$

c. Korelasi antara $X_{1}$ dengan $X_{2}$

$\mathrm{r}_{y 12}$

$=\frac{n \cdot\left(\sum \mathrm{X}_{1} \mathrm{X}_{2}\right)-\left(\sum \mathrm{X}_{1}\right) \cdot\left(\sum \mathrm{X}_{2}\right)}{\sqrt{\left\{\mathrm{n} \cdot \sum \mathrm{X}_{1}^{2}-\left(\sum \mathrm{X}_{1}\right)^{2}\right\} \cdot\left\{\mathrm{n} \cdot \sum \mathrm{X}_{2}^{2}-\left(\sum \mathrm{X}_{2}\right)^{2}\right\}}}$

$\mathrm{r}_{y 12}$

$=\frac{13792-137080}{\sqrt{\{55300-52900\} .\{379800-355216\}}}$ 845

$\mathrm{r}_{y 12}=\frac{845}{\sqrt{\{2400\} .\{24584\}}}$

$r_{y 12}=\frac{845}{\sqrt{.(59001600)}}$

$r_{y 12}=\frac{845}{7681,249}$

$\mathrm{ry}_{12}=0,110$

d. Rumus korelasi berganda $\mathrm{r}_{1 \cdot 2}=$ Koefisien korelasi variable

$\mathrm{X} 1$ dan $\mathrm{X} 2$

$$
\begin{aligned}
R_{y_{\cdot 12}} & =\sqrt{\frac{r_{y_{1}}^{2}+r_{y_{2}}^{2}-2 r_{y_{1}} r_{y_{2}} r_{y_{12}}}{1-r_{12}^{2}}} \\
= & \sqrt{\frac{(0,499)^{2}+(0,471)^{2}-2(0,499)(0,471)(0,110)}{1-0,110^{2}}} \\
R_{y_{\cdot 12}} & =\sqrt{\frac{0,423-2 \cdot(0,023)}{0,987}} \\
R_{y_{\cdot 12}} & =\sqrt{\frac{0,470-0,046}{0,987}} \\
R_{y_{\cdot 12}} & =\sqrt{\frac{0,376}{0,987}} \\
R_{y_{\cdot 12}} & =\sqrt{0,381} \\
R_{y_{\cdot 12}} & =0,617
\end{aligned}
$$

\section{Menguji Nilai $r$}

Dari hasil penghitungan nilai, selanjutnya melihat nilai $r_{\text {tabel }}$ pada taraf sigifikan $5 \%$ dimana $\mathrm{N}=25$ maka diketahui nilai $\mathrm{r}_{\text {tabel }}$ adalah0,396, maka dilakukan pengujian nilai $r_{\text {hitung: }}$ :

a. Hubungan kekuatan otot lengan dengan jauhnya lemparan turbo pada siswa kelas V SDN 2 Gerunung tahun pelajaran 2016/2017 diketahui nilai $r_{\text {hitung }} 0,499$ dan $\mathrm{r}_{\text {tabel }} 0,396$, maka $\mathrm{r}_{\text {hitung }}$ lebih besar daripada $\mathrm{r}_{\text {tabel }}$ yaitu 0,499>0,396.

b. Hubungan keseimbangan statis dengan jauhnya lemparan turbo pada siswa kelas V SDN 2 Gerunung tahun pelajaran 2016/2017 diketahui nilai $r_{\text {hitung }} 0,471$ dan $\mathrm{r}_{\text {tabel }} 0,396$, maka $\mathrm{r}_{\text {hitung }}$ lebih besar daripada $\mathrm{r}_{\text {tabel }}$ yaitu 0,471 >0,396.

c. Hubungan kekuatan otot lengan dengan keseimbangan statis diketahui nilai $\mathrm{r}_{\text {hitung }} 0,110$ dan $\mathrm{r}_{\text {tabel }} 0,396$, maka $\mathrm{r}_{\text {hitunglebih }}$ kecil daripada $r_{\text {tabel }}$ yaitu $0,110<0,396$.

d. Hubungan kekuatan otot lengan dan keseimbangan stastis dengan jauhnya lemparan turbo diketahui nilai $r_{\text {hitung }} 0,617$ dan $r_{\text {tabel }}$ 0,396, maka $r_{\text {hitung }}$ lebih besar daripada rtabel yaitu $0,617>0,396$.

\section{Menarik Interpretasi Hasil}


a. Dari hasil pengujian nilai $r$ dimana $r_{\text {hitung }}$ lebih besar dari $r_{\text {tabel }} 0,499>0,396$, maka hipotesis nihil $\left(\mathrm{H}_{0}\right)$ ditolak dan $\left(\mathrm{H}_{\mathrm{a}}\right)$ diterima, maka hasil analisis dalam penelitian ini adalah sebagai berikut :"Ada Hubungan Kekuatan Otot Lengan dengan Jauhnya Lemparan Turbo .

b. Dari hasil pengujian nilai $r$ dimana $r_{\text {hitung }}$ lebih besar dari $r_{\text {tabel }} 0,471>0,396$, maka hipotesis nihil $\left(\mathrm{H}_{0}\right)$ ditolak dan $\left(\mathrm{H}_{\mathrm{a}}\right)$ diterima, maka hasil analisis dalam penelitian ini adalah sebagai berikut :"Ada Hubungan Keseimbangan statisdengan Jauhnya Lemparan Turbo .

c. Dari hasil pengujian nilai $r$ dimana $r_{\text {hitung }}$ lebih besar dari $r_{\text {tabel }} 0,110<0,396$, maka hipotesis nihil $\left(\mathrm{H}_{0}\right)$ diterima dan $\left(\mathrm{H}_{\mathrm{a}}\right)$ ditolak , maka hasil analisis dalam penelitian ini adalah sebagai berikut :"Tidak ada Hubungan Kekuatan Otot Lengan dengan keseimbangan statis Dari hasil pengujian nilai $r$ dimana $r_{\text {hitung }}$ lebih besar dari $\mathrm{r}_{\text {tabel }} 0,617>0,396$, maka hipotesis nihil $\left(\mathrm{H}_{0}\right)$ ditolak dan $\left(\mathrm{H}_{\mathrm{a}}\right)$ diterima, maka hasil analisis dalam penelitian ini adalah sebagai berikut :"Ada Hubungan Kekuatan Otot Lengan dan keseimbangan statis dengan Jauhnya Lemparan Turbo Berdasarkan hasil analisis data dan kesimpulan dapat dijelaskan bahwa ada hubungan kekuatan otot lengan dan kesimbangan statis dengan jauhnya lemparan turbo Hal ini dibuktikan dari hasil penelitian yang telah dilakukan dimana $r_{\text {hitung }}$ lbih besar dari $r t_{\text {abelpada taraf }}$ signifikan $5 \%$ yakni $r_{\text {hitung }}>r_{\text {tabel }}(0,617>$ 0,396 ).Berdasarkan hasil analisis data dan kesimpulan dapat dijelaskan bahwa keberhasilan melakukan lempar turbo pada olahraga cabang lempar turbo dapat disebabkan oleh beberapa faktor antara lain, kekuatan otot lengan dan Kesimbangan statis.

Faktor tersebut merupakan faktor yang dominan yang dapat mempengaruhi keberhasilan dalam melakukan lemparan. Oleh karena itu untuk lebih maksimal hasil dalam melakukan lemparan mendapat perhatian ke tiga faktor tersebut, khususnya dalam melakukan lemparan dan latihan perlu dilakukan secara rutin serta diberikan sesuai dengan karakteristik yang tepat pada cabang olahraga lempar turbo sehingga apa yang ingin dicapai sesuai dengan yang diharapkan.

\section{SIMPULAN DAN SARAN}

Berdasarkan hasil analisis data dan pembahasan dapat disimpulkan bahwa:

1. Ada hubungan kekuatan otot lengan dengan jauhnya lemparan turbo Ada hubungan keseimbangan statis dengan jauhnya lemparan turbo Tidak ada hubungan kekuatan otot lengan dan keseimbangan statis

2. Ada hubungan kekuatan otot lengan dan keseimbangan statis dengan jauhnya lemparan Berdasarkan hasil penelitian dan kesimpulan diatas, maka penyusun dapat mengajukan saran-saran sebagai berikut:

a. Bagi Pembina dan pelatih olahraga pada khususnya hendaknya dapat memperhatikan beberapa hal yang dapat meningkatkan prestasi pada olahraga lempar turbo.

b. Bagi SDN 2 Gerunung hendaknya memperhatikan fasilitas yang dapat mendukung tercapainy aprestasi siswa yang lebih baik.

c. Bagi siswa yang ingin berprestasi agar sesering mungkin latihan untuk kekuatan keseimbangan statis dan faktor-faktor yang lain agar memperoleh prestasi yang maksimal, khususnya dalam olahraga lempar turbo.

d. Diharapkan pada peneliti-peneliti lain, agar memperluas permasalahan seperti variabel-variabel penelitian sehingga dapat memperkaya ilmu pengetahuan atletik, khususnya lempar turbo.

\section{REFERENSI}

Adi, Winendra. 2008. Seri Olagraga Atletik. Yogyakarta: Pustaka Insan Madani.

Furchan, A. 2004.Pengantar Pendidikan Dalam Penelitian. Yogyakarta: Pustaka Pelajar.

Harsono. 1988. Prinsip-prinsip pelatihan olahraga. Jakarta: Bahan Penataran Pelatihan Pelatihan Olahraga PIOKONI Pusat. 
Hidayat, A. 2010. Metode penelitian kesehatan. Surabaya: Health Book Publishing.

Hulfian, L. 2014. Statistik Dikjas. Mataram: Genilis.

Ichsan, H. 2004. Tes dan pengukuran kesegaran jasmani.Makasar:Universitas Negeri Makasar.

Ikip, Mataram.2011, pedoman pembimbingan dan penulisan karya ilmiah; institut keguruan dan ilmu pendidikan ikip mataram.

Jerver, J 1996. Belajar dan berlatih atletik. Bandung: Pioner Jaya

Maksum, A. 2009.Metode Penelitian Dalam Olahraga. Surabaya: Fakultas Ilmu Keolahragaan-Universitas Negri Surabaya.

Munasifah. 2008. Jurnal Ilmu Keolahragaan. Medan: Universitas Negeri Medan.

Ngatiyono.2007. Pendidikan Jasmani dan Kesehatan 1. Solo: tiga Serangkai Pustaka Mandiri.

Nurhasan.(2005). Aktivitas Kebugaran. Jakarta: Depdiknas

O'Sullivan, 1981.Physical Rehabilitation Evaluation \& Treatment Procedures, F.A Davis Company, Philadelpia.

PASI.(1988), Persatuan Perlombaan Athletik, ED. 1986, Percetakan Enka Parahiyangan.

Rusli Lutan. (2000). "Strategi Belajar Mengajar Penjaskes". Yogyakarta: Depdiknas.

Sajoto. 1995. Pengembangan dan Pembinaan Kekuatan kondisi Fisik Dalam

Olahraga.Jakarta: Dahara Prize.

Sogiyono , 2010. Metode Penelitian Kuantitatif, Kualitatif, dan R\&D. Bandung: alfabeta.

Suharno.(1981). Ilmu Coching Umum. Yogyakarta: IKIP Yogyakarta.

Tamsir R, 1985. Petunjuk Atletik.Yogyakarta: Cetakan II.

Wiarto Giri, 2013. Atletik. Yogyakarta : Graha Ilmu 